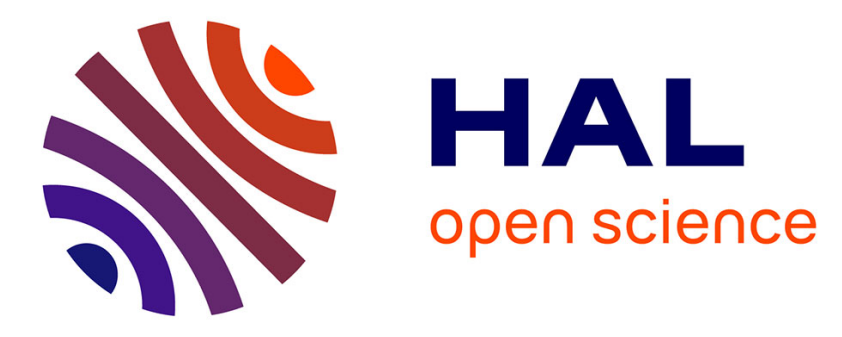

\title{
Dietary Cadmium and Benzo(a)pyrene Increased Intestinal Metallothionein Expression in the Fish
}

\author{
G. Roesijadi, S. Rezvankhah, A. Perez-Matus, A. Mitelberg, K. Torruellas, \\ P.A. van Veld
}

\section{- To cite this version:}

G. Roesijadi, S. Rezvankhah, A. Perez-Matus, A. Mitelberg, K. Torruellas, et al.. Dietary Cadmium and Benzo(a)pyrene Increased Intestinal Metallothionein Expression in the Fish. Marine Environmental Research, 2008, 67 (1), pp.25. 10.1016/j.marenvres.2008.10.002 . hal-00563060

\section{HAL Id: hal-00563060 \\ https://hal.science/hal-00563060}

Submitted on 4 Feb 2011

HAL is a multi-disciplinary open access archive for the deposit and dissemination of scientific research documents, whether they are published or not. The documents may come from teaching and research institutions in France or abroad, or from public or private research centers.
L'archive ouverte pluridisciplinaire HAL, est destinée au dépôt et à la diffusion de documents scientifiques de niveau recherche, publiés ou non, émanant des établissements d'enseignement et de recherche français ou étrangers, des laboratoires publics ou privés. 


\section{Accepted Manuscript}

Dietary Cadmium and Benzo(a)pyrene Increased Intestinal Metallothionein Expression in the Fish Fundulus heteroclitus

G. Roesijadi, S. Rezvankhah, A. Perez-Matus, A. Mitelberg, K. Torruellas, P.A. Van Veld

PII:

S0141-1136(08)00218-3

DOI:

10.1016/j.marenvres.2008.10.002

Reference:

MERE 3294

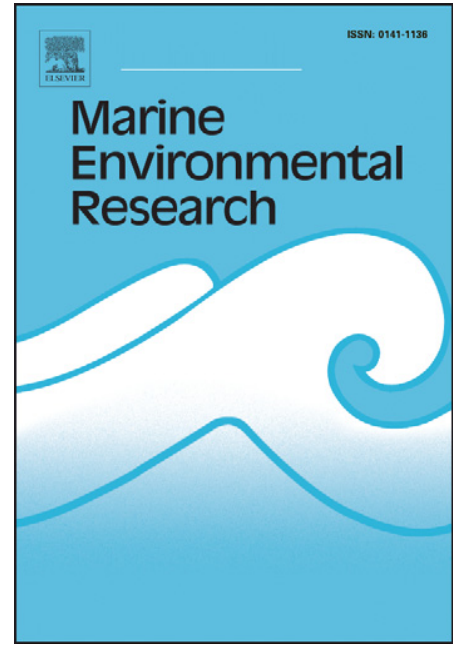

To appear in:

Marine Environmental Research

Received Date:

8 August 2008

Revised Date:

6 October 2008

Accepted Date:

7 October 2008

Please cite this article as: Roesijadi, G., Rezvankhah, S., Perez-Matus, A., Mitelberg, A., Torruellas, K., Van Veld, P.A., Dietary Cadmium and Benzo(a)pyrene Increased Intestinal Metallothionein Expression in the Fish Fundulus heteroclitus, Marine Environmental Research (2008), doi: 10.1016/j.marenvres.2008.10.002

This is a PDF file of an unedited manuscript that has been accepted for publication. As a service to our customers we are providing this early version of the manuscript. The manuscript will undergo copyediting, typesetting, and review of the resulting proof before it is published in its final form. Please note that during the production process errors may be discovered which could affect the content, and all legal disclaimers that apply to the journal pertain. 
1 Running Head: Metallothionein and dietary cadmium in fish

2 Title of article: Dietary Cadmium and Benzo(a)pyrene Increased Intestinal Metallothionein

3 Expression in the Fish Fundulus heteroclitus

4

5 Author's complete names: G. Roesijadi ${ }^{\mathrm{a}^{* 1}}$, S. Rezvankhah ${ }^{\mathrm{a}}$, A. Perez-Matus ${ }^{\mathrm{a}}$, A. Mitelberg, K.

6 Torruellas ${ }^{\mathrm{a}}$, P. A. Van Veld

7

8 Institutional address:

$9{ }^{a}$ Florida Atlantic University, Department of Biological Sciences, 777 Glades Road, Boca Raton,

$10 \quad$ FL 33431

11 'Virginia Institute of Marine Science, Gloucester Point, VA

12

13 "Corresponding author.

14 Tel.: 360-582-253; fax: 360-681-4559

15 E-mail address: g.roesijadi@pnl.gov

16

$17{ }^{1}$ Current Address: Pacific Northwest National Laboratory, Environment and Energy Directorate, 18 Marine Science Division, 1529 West Sequim Bay Road, Sequim, WA 98382 
19 Abstract

20

21 Fish were individually fed food pellets containing cadmium, benzo(a)pyrene, or a

22 combination of the two, then analyzed for metallothionein mRNA expression in the intestine,

23 liver, and gill using real-time RT-qPCR. An initial experiment using only cadmium showed that

24 ingestion of pellets varied in individual fish, and estimates of cadmium dose from the numbers of

25 ingested pellets indicated considerable individual variability in cadmium dose. Induction of

26 intestinal metallothionein mRNA was apparent, however, and a linear dose-response relationship

27 was observed for metallothionein expression and cadmium dose in the intestine, but not the other

28 organs, which showed no induction. In a second experiment, the entire daily cadmium dose was

29 provided in a single contaminated pellet that was consumed by all treated fish, effectively

30 eliminating the effect of variable ingestion rates on dose, and the interaction between cadmium

31 and benzo(a)pyrene was also investigated. The intestine was again the primary organ for

32 metallothionein induction by cadmium. When benzo(a)pyrene was administered together with

33 cadmium, induction of metallothionein was potentiated by the presence of benzo(a)pyrene, with

34 the main effect seen in the intestine, where already high levels of induction by cadmium alone

35 increased by 1.74 -fold when benzo(a)pyrene was present.

37 Keywords: Metallothionein; Metals; Hydrocarbons; Metal-organic interactions; mRNA; Fish 


\section{Introduction}

Organs at the environmental-organism interface, which are involved in uptake processes, are

41 important in the absorption of metals from the environment and especially useful in analyzing

42 events associated with dietary exposure (Harrison et al., 1989; Thomann et al., 1997). In higher

43 animals, dietary cadmium absorption is characterized by high levels of cadmium in the intestinal

44 mucosa and its slow transfer to other internal organs (Elsenhans et al., 1997). About 60\% of

45 cadmium in the mucosa of the small intestine is bound to the metal-binding protein

46 metallothionein shortly after dietary exposure (Lehman et al., 1986). Metallothionein is involved

47 in intestinal cadmium absorption through its induction and binding of cadmium. Subsequent

48 interorgan cadmium transport out of the intestine is, in part, associated with serosal release as

49 cadmium-metallothionein complexes (Zalups et al., 2003). For dietary exposure to cadmium in

50 fish such as salmon and rainbow trout, the intestine is also the site of absorption and the portal

51 for redistribution via the systemic circulation, resulting in both cadmium accumulation and

52 toxicity in other organs (Baldisserotto et al., 2005; Baldisserotto et al., 2006; Berntssen et al.,

53 2001a; Berntssen et al., 2001b; Berntssen et al., 2000; Berntssen et al., 2003; Franklin et al.,

54 2005; Lundebye et al., 1999; Ng et al., 2008; Thomann et al., 1997). Although the proportion of

55 cadmium that crosses the gut for transport other organs is relatively low (Franklin et al., 2005;

$56 \mathrm{Ng}$ et al., 2008), the dietary exposure route is considered significant in the movement of

57 cadmium through food chains (Dallinger et al., 1987; Harrison et al., 1989; Wallace et al., 2003).

58 While it is known that metallothionein is induced in fish intestines in response to dietary

59 cadmium (Berntssen et al., 2001a; Chowdhury et al., 2005) and that, as noted above, the intestine

60 is the site of absorption of dietary cadmium, there is still little information on the response of fish

61 intestinal metallothionein to dietary cadmium exposure. It is reported that intestinal 
62 metallothionein is induced in response to water-borne cadmium in the killifish Fundulus

63 heteroclitus, a ubiquitous inhabitant of estuarine environments along the North American

64 Atlantic coastline (Van Cleef-Toedt et al., 2001). Yet similar induction of killifish intestinal

65 metallothionein in response to dietary cadmium has yet to be reported. Moreover, because

66 exposures in the natural environment are likely to be to mixtures of substances that include

67 hydrocarbons as well as metals (Rana, 2006), the potential modulation of cadmium-induced

68 metallothionein induction by polycyclic aromatic hydrocarbons such as benzo(a)pyrene, an

69 environmental mutagen, is also of interest. Our objective was to determine the effect of dietary

70 exposure to cadmium and co-exposure to benzo(a)pyrene on metallothionein induction in $F$.

71 heteroclitus, focusing on expression of the metallothionein mRNA in the intestine, liver, and gill.

\section{2. Materials and methods}

2.1. Fish

Individuals of Fundulus heteroclitus were collected from reference sites in Chesapeake Bay

78 (e.g., Van Veld et al., 1997; Vogelbein et al., 1990) for the experiments described below. They

79 were maintained in aquaria containing $120 \mathrm{~L}$ recirculating synthetic seawater (Instant Ocean,

80 Aquarium Systems, Inc., in charcoal-filtered, deionized water) at 20 psu and either 20 or $25^{\circ} \mathrm{C}$,

81 depending on the ambient temperature at the time of collection. Aquaria were outfitted with

82 Skilter Power Filters (Aquatic Ecosystems, Inc., Apopka, FL). Fish were initially fed a

83 commercial flake food (Aquatox Food, Aquatic Ecosystems, Inc., Apopka, FL), supplemented

84 by pellets prepared from Gel Fish Food (Aquatic Ecosystems, Inc., Apopka, FL) (see below for 
85 food preparation). Fish were trained to eat food pellets described below during the maintenance

86 period.

2.2. Preparation of food pellets

89

90

Gel Fish Food powder (45 g) was added to heated water (48 $\mathrm{ml}$ ) according to the

91 manufacturer's instructions. Pellets made from this unamended mixture were fed to the fish

92 during the maintenance phase in aquaria. Control pellets prepared for the exposures to cadmium

93 or benzo(a)pyrene received appropriate volumes of the carrier solvents, added to the Gel Fish

94 Powder slurry before allowing the mixture to gel. The resultant slurry was poured between two

95 glass electrophoresis plates separated by $1.5 \mathrm{~mm}$ spacers and allowed to gel at $4^{\circ} \mathrm{C}$. Once

96 solidified, $3 \mathrm{~mm}$ diameter discs weighing approximately 8.5 to $10 \mathrm{mg}$ wet weight were cut from

97 the gel sheets using punches from an immunodiffusion punch set (Gelman Sciences Inc [now

98 Pall Life Sciences, Inc.]), Ann Arbor, MI).

99

100

To make cadmium-contaminated food for the first, preliminary, experiment, $72 \mu \mathrm{l}$ of a $5 \mathrm{M}$

101 stock solution of $\mathrm{CdCl}_{2}$ in $0.01 \mathrm{~N}$ nitric acid was added during preparation of the Gel Fish Food.

102 A comparable volume of $0.01 \mathrm{~N}$ nitric acid, which did not measurably alter $\mathrm{pH}$, was added to the

103 control food. The cadmium content was $5.7 \mu \mathrm{g}$ cadmium per pellet, equivalent to $1.2 \mu \mathrm{g}$

104 cadmium per mg dry weight. Cadmium-exposed fish were fed only the cadmium-laden pellets.

105 Control pellets contained the dilute $\mathrm{HNO}_{3}$ solvent carrier only, and averaged $5.9 \times 10^{-4} \mu \mathrm{g}$

106 cadmium per pellet, equivalent to $1 \times 10^{-4} \mu \mathrm{g}$ cadmium per mg dry pellet weight. 
For the second follow-on experiment, the preparation of contaminated pellets was modified

109 to minimize the effect of individual variability in pellet consumption on dose observed in the

110 first experiment (see below). For this experiment, a single pellet contained the entire daily dose

111 of cadmium, benzo(a)pyrene, or cadmium plus benzo(a)pyrene. To make the cadmium-laden

112 pellets, $720 \mu \mathrm{l}$ of a $5 \mathrm{M} \mathrm{CdCl}_{2}$ in $0.01 \mathrm{~N} \mathrm{HNO}_{3}$ plus $0.9 \mathrm{ml}$ cod liver oil was added to the Gel

113 Fish Food slurry to provide $36.1 \mu \mathrm{g}$ cadmium per pellet, equivalent to $9.0 \mu \mathrm{g}$ cadmium per mg

114 dry weight pellet. To make benzo(a)pyrene laden pellets, $0.9 \mathrm{ml}$ of $10.35 \mathrm{mg}$ per $\mathrm{ml}$

115 benzo(a)pyrene in cod liver oil plus $720 \mu \mathrm{l}$ of $0.01 \mathrm{~N} \mathrm{HNO}_{3}$ was added to the Gel Fish Food

116 slurry to provide a dose of $0.83 \mu \mathrm{g}$ benzo(a)pyrene per pellet at a concentration of $0.21 \mu \mathrm{g}$

117 benzo(a)pyrene per mg dry pellet weight. The combined cadmium-benzo(a)pyrene laden pellets

118 contained similar amounts of cadmium and benzo(a)pyrene. All exposure pellets contained the

119 same carrier solvent background of $0.01 \mathrm{~N} \mathrm{HNO}_{3}$ plus cod liver oil. Control pellets contained

120 similar volumes of the carrier solvents $0.01 \mathrm{~N} \mathrm{HNO}_{3}$ and cod liver oil, but no cadmium or

121 benzo(a)pyrene.

122

123 2.3. Experiments

125 The fish used in the two experiments were obtained in different collections separated by time

126 and seasons (September versus January). For experiments, fish (mean weight $8.3 \mathrm{~g}$ in the first

127 experiment and $7.9 \mathrm{~g}$ in the second experiment) were transferred individually from maintenance

128 tanks to separate glass containers (one fish per $17 \mathrm{~cm}$ height, $15 \mathrm{~cm}$ diameter container)

129 containing 1.5 liters Instant Ocean at $20 \mathrm{psu}$ and $25^{\circ} \mathrm{C}$ in the first experiment and $20^{\circ} \mathrm{C}$ in the

130 second experiment. Aeration was supplied to each container by slow bubbling through a Pasteur

131 pipette. Water was replaced every other day. Fish were maintained on a light:dark cycle of $12 \mathrm{~h}$ 
132 light:12 $\mathrm{h}$ dark. Fish were acclimated to the experimental containers for three days prior to the

133 exposure to dietary cadmium. During this period, fish were fed control pellets administered one-

134 at-a-time by hand. The acclimation period was followed by dietary exposure during a seven-day

135 experimental period.

136

137 In the first experiment, fish were fed either cadmium-laden or control pellets by hand once a

138 day to either satiation or up to a limit of 15 pellets per fish over the course of the seven day

139 experiment. Fish were not fed on the seventh day, when they were sacrificed for harvest of

140 organs. Cadmium-exposed fish were fed only cadmium-laden pellets, and control fish were fed

141 only control pellets. Each ingested pellet was swallowed whole, immediately after

142 administration. Uneaten pellets were immediately removed to minimize their contact time with

143 the water and leaching of contaminants to the external medium. None of the fish consumed the

144 maximum number of pellets allotted for this experiment, and there was individual variability in

145 the total number of pellets consumed. The average daily consumption was about nine pellets per

146 day. The associated individual variability in the cumulative cadmium dose enabled us to analyze

147 the responses of individuals as a function of dose.

149 In order to better control the dose in the second experiment, the dosing protocol was

150 modified to insure that each fish received the same total amount of cadmium and benzo(a)pyrene

151 over the course of the experiment. To do this, fish in the second experiment were provided a

152 single experimental pellet containing the daily dose of cadmium, benzo(a)pyrene, cadmium plus

153 benzo(a)pyrene combination, or control treatments, followed by the remainder of the daily ration

154 of up to nine control pellets each day for seven days, roughly similar to the average daily

155 consumption of nine pellets per day in the first experiment. Fish were sacrificed on the eighth 
156 day. All fish in this experiment consumed the daily dose of treatment pellets and, with a few

157 exceptions, also consumed the total control pellet ration provided immediately after the treatment 158 pellet was eaten.

160 At the end of exposures, the fish were immobilized using a combination of concentrated 161 sodium bicarbonate (Noga, 2000) in an ice-cold Instant Ocean slurry. The intestine, liver, and

162 gill were excised, weighed, and frozen in liquid nitrogen. Samples were stored at $-80^{\circ} \mathrm{C}$ until 163 analyzed for metallothionein mRNA levels.

\subsection{RNA isolation}

167 Total RNA for the first experiment was extracted from frozen tissue using Tri Reagent

168 (Molecular Research Center, Inc., Cincinnati, OH) per manufacturer's instructions, of which 10

$169 \mu \mathrm{g}$ was treated with DNase using the Promega RQ1 DNase 1 kit and protocols (Fitchburg, WI).

170 Immediately following DNase treatment, the RNA was purified using the Qiagen RNeasy kit

171 (Qiagen, Valencia, CA) following manufacturer's instructions. RNA was eluted in $30 \mu 1$ of

172 DEPC-treated $\mathrm{H}_{2} \mathrm{O}$. Subsequent RNA extractions used the RNeasy MiniKit (Qiagen, Valencia,

173 CA), followed by treatment with DNase (RNase-Free DNase kit, Qiagen, Valencia, CA).

175 2.5. Identification of metallothionein and 18S RNA sequences in Fundulus heteroclitus

177 Metallothionein and 18S RNA sequences were amplified by reverse transcriptase polymerase

178 chain reaction (RT-PCR) using consensus fish metallothionein primers, gel purified by agarose 179 gel electrophoresis, then sent to the University of Florida's Interdisciplinary Center for 
180 Biotechnology Research (UFICBR) for sequence verification. This laboratory used ABI Prism

181 BigDye Terminator cycle sequencing protocols (part number 4336776) developed by Applied

182 Biosystems (Perkin-Elmer Corp., Foster City, CA). Sequences for forward and reverse primers

183 were provided to UFICBR for sequencing the sense and antisense strands. The amplified

184 sequences served as templates for design of real-time PCR primers (Invitrogen's Lux ${ }^{\mathrm{TM}}$ Designer

185 software).

186

187 2.6. Real-time qPCR

188

189 Real-time PCR reactions used cDNA libraries as template for amplification of metallothionein

190 and 18S RNA sequences. For construction of cDNA libraries, $1 \mu \mathrm{g}$ DNase-treated total RNA

191 was hybridized with $500 \mathrm{ng}$ of random hexamers at $70^{\circ} \mathrm{C}$ for 5 minutes. For reverse

192 transcription, one $\mu \mathrm{l}$ of this mixture and a cocktail containing $4 \mu \mathrm{l}$ of $5 \mathrm{X}$ buffer, $2 \mu \mathrm{l}$ of $10 \mathrm{mM}$

193 stock of dNTPs, $0.5 \mu$ l of $40 \mathrm{U}$ per $\mu \mathrm{l}$ stock of RNase inhibitor, and $1 \mu \mathrm{l}$ of $200 \mathrm{U}$ per $\mu \mathrm{l}$ stock of

194 M-MLV RT enzyme was incubated at $37^{\circ} \mathrm{C}$ for 60 minutes, $95^{\circ} \mathrm{C}$ for 5 minutes, then placed on 195 ice for 5 minutes.

196

197 Real-time PCR reactions contained $23.8 \mu$ l of autoclaved Nanopure water (Barnstead), $25 \mu 1$

198 Platinum Quantitative PCR Supermix-UDG (Invitrogen, Carlsbad, Ca), $0.1 \mu$ appropriate

199 Lux ${ }^{\mathrm{TM}}$ Fluorogenic Primers ((Invitrogen, Carlsbad, Ca; stock concentration $\left.100 \mu \mathrm{M}\right)$, and $1 \mu \mathrm{l}$ of

200 the cDNA library. Temperature programming followed the manufacturer's recommendations for

201 Lux ${ }^{\mathrm{TM}}$ Fluorogenic Primers and Platinum Quantitative PCR Supermix-UDG: $50^{\circ} \mathrm{C}$ for 2 min;

$20295^{\circ} \mathrm{C}$ for $2 \mathrm{~min}$; and 45 cycles of $95^{\circ} \mathrm{C}, 15 \mathrm{sec} ; 55^{\circ} \mathrm{C}, 30 \mathrm{sec}$; and $72^{\circ} \mathrm{C}, 30 \mathrm{sec}$. Reactions were 
203 conducted in an MJResearch (now Bio-Rad Laboratories) DNA Engine Opticon 2. Each sample

204 was analyzed in replicates of two using the Lux ${ }^{\mathrm{TM}}$ Fluorogenic Primers derived from sequences

205 confirmed as those for Fundulus heteroclitus metallothionein and 18S RNA. The threshold cycle

$206\left(C_{t}\right)$ for each amplification was used to calculate the $2^{-\Delta \Delta C t}$ for relative expression of

207 metallothionein mRNA (Livak et al., 2001). $\Delta \Delta \mathrm{C}_{\mathrm{t}}$ is the $\mathrm{C}_{\mathrm{t}}$ of metallothionein mRNA target

208 minus the $\mathrm{C}_{\mathrm{t}}$ of the endogenous 18S RNA and the $\mathrm{C}_{\mathrm{t}}$ of the 18S RNA of the plate calibrator

209 sample that was added to every plate. To validate the assumption of similar amplification

210 efficiencies for the target and reference specified by the $2^{-\Delta \Delta \mathrm{Ct}}$ method (Livak et al., 2001),

211 dilutions were amplified for the genes of interest. The slopes for plots of $\mathrm{C}_{\mathrm{t}}$ 's versus $\log$ dilution

212 for both metallothionein and the $18 \mathrm{~S}$ mRNA were found not to be significantly different from

213 zero in all cases.

214

215 2.7. Statistical analysis

216

217 The data were analyzed by analysis of variance with post hoc analysis using the Tukey HSD post

218 hoc test, using the JMP software package ${ }^{\mathrm{TM}}$ (SAS Institute, Cary, NC). Linear regression was

219 conducted with the JMP software package ${ }^{\mathrm{TM}}$ and Kaleidagraph (Synergy Software; Reading, PA).

221 3. Results

222

Initial efforts confirmed the identities of target sequences as those for metallothionein and

224 18S RNA. Amplified sequences for intestinal, liver, and gill metallothionein exhibited 95\% or 225 greater identity with Fundulus heteroclitus metallothionein (NCBI accession numbers:

226 CN968347 and AB426465). That for the putative 18S RNA aligned with 98\% identity with the 
227

228

229

230

231

232

233

234

235

236

237

238

239

240

241

242

243

244

245

246

247

248

F. heteroclitus 18S RNA sequence (NCBI accession number: M91180). These findings confirmed the identity of the metallothionein and 18S RNA sequences for our experimental population of $F$. heteroclitus, and these amplified sequences served as templates for design of Lux $^{\mathrm{TM}}$ Fluorogenic Primers for real-time PCR.

Representative real-time amplification profiles and $\mathrm{C}_{\mathrm{t}}$ 's for intestinal, liver, and gill metallothionein from the first experiment are shown in Figure 1 . The $2^{-\Delta \Delta C t}$ values were calculated from the $\mathrm{C}_{\mathrm{t}}$ 's as previously described. In controls of both experiments, respective levels in the gill, liver, and intestine were low and roughly equivalent, with those of gills consistently lower than in the liver and intestine (Tables 1 and 2).

In the first experiment, significant induction of metallothionein by cadmium was seen only in the intestine, which exhibited a 10.7-fold average increase in metallothionein mRNA in cadmium-exposed fish in comparison with controls; metallothionein was not induced in liver and gill (Table 1). The central tendencies represented by the means of Table 1 masked the effect of individual variability in food consumption noted in the Materials and Methods section and the resultant individual variability in cadmium dose over the course of exposure [average cumulative dose of cadmium-exposed fish over six days: $45.9 \pm 7.2$ (S.E.) $\mu \mathrm{g}$ cadmium $/ \mathrm{g}$ fish]. There was a dose-dependent linearity between cadmium dose and induction of intestinal metallothionein when all samples, including controls and those exposed to cadmium, were plotted (Fig. 2). In comparison, there was no measurable effect on metallothionein mRNA levels in liver and gills as the cumulative cadmium dose increased. 
In the second experiment, the individual variability in dose noted previously was controlled by loading the entire daily cadmium dose for each fish into a single pellet. All fish ate the daily exposure pellet, and, unlike the situation in the first experiment, all cadmium- and benzo(a)pyrene-exposed fish received the same cumulative dose $(32.0 \mu \mathrm{g}$ cadmium per $\mathrm{g}$ fish and/or $0.74 \mu \mathrm{g}$ benzo(a)pyrene per $\mathrm{g}$ fish) over the course of the seven day exposure period. The

255 cumulative cadmium dose per $\mathrm{g}$ fish in this experiment was not significantly different from those 256 of the first experiment (Student's t-test; $\mathrm{p}>0.05$ ). Induction in the intestine by cadmium alone

257 resulted in a 20-fold increase over control levels (Table 2), whereas metallothionein mRNA

258 levels in the gill and liver of cadmium-exposed fish were not significantly different from those of 259 controls (Table 2). This pattern of organ-specific induction of metallothionein by dietary

260 cadmium was similar to that described above for the first experiment, although the magnitude of

261 induction in the intestine was lower in the first experiment. Differences in collection history and 262 seasons are possible contributing factors. Benzo(a)pyrene alone did not induce metallothionein in

263 the second experiment, although it appears that benzo(a)pyrene potentiated induction of

264 intestinal metallothionein mRNA by cadmium, causing an approximate 1.74 -fold increase over 265 that by cadmium alone.

\subsection{Discussion}

Our findings showed that intestinal metallothionein was induced to relatively high levels in

270 the intestine and that intestinal metallothionein induction was dependent on the ingested

271 cadmium dose. Metallothionein in liver and gill, on the other hand, was not significantly induced

272 by dietary cadmium. In feeding studies such as this, individual variability in ingestion can affect

273 both the dose to individuals and the dose-response relationship, revealed by linear regression 
274 analysis of intestinal metallothionein mRNA levels versus cadmium dose in the current study. It

275 is not uncommon in studies on dietary exposure of fish to toxic substances to maintain multiple

276 individuals in single containers and to feed fish by broadcast feeding of contaminated food to all

277 individuals in a container. Although central tendencies in measured responses can be estimated

278 in such cases, they can also be obscured by individual differences due to individual variability in

279 ingestion of contaminated food. Closely monitoring and controlling ingestion of contaminated

280 food by individual fish allowed us to minimize one component of the variance associated with

281 ingested dose.

282

283 The lack of induction of hepatic and gill metallothionein in our study is believed to be due to

284 slow transport of cadmium across the intestine to other organs and negligible waterborne

285 cadmium exposure over the course of our experiments. This is consistent with studies on

286 rainbow trout in which $93 \%$ or greater of the cadmium administered via a dietary path fails to

287 cross the gut wall (Chowdhury et al., 2004a; Franklin et al., 2005; Ng et al., 2008). Induction of

288 metallothionein in organs such as kidney, liver, and gill would be expected to occur following

289 protracted exposure and export of cadmium from the intestine (Berntssen et al., 2001a;

290 Chowdhury et al., 2005). Thus, after dietary cadmium exposure of one month and longer,

291 cadmium accumulation in the liver, gill, and kidney of rainbow trout and Atlantic salmon is

292 elevated, but generally remains lower than those detected in intestinal tissues (Berntssen et al.,

293 2001a; Chowdhury et al., 2005; Szebedinszky et al., 2001). It was suggested from experiments

294 on rainbow trout that the gut wall serves as a barrier that reduces cadmium transfer to internal

295 tissues (Franklin et al., 2005). The low efficiency of gastrointestinal transfer of cadmium,

296 whether associated with prey (0.9-6.4\%) (Ng et al., 2008) or with cadmium-spiked commercial

297 food $(<0.1 \%$ ) (Franklin et al., 2005) is comparable to that reported for higher animals of 3-6\% 
298 (ATSDR, 1999). It is therefore not unexpected that the short-term cellular response in Fundulus

299 heteroclitus would be heightened in the intestine, which is exposed directly during dietary

300 exposures, in comparison with other organs that depend on interorgan transport from the

301 intestine for cadmium exposure.

302

303 Induction of metallothionein, enhanced cadmium binding capacity in intestinal cells, and

304 gradual transfer of cadmium-metallothionein complexes across the serosal membrane to other

305 organs are proposed as mechanisms to protect against the rapid accumulation of cadmium by

306 internal organs (Elsenhans et al., 1997). Our finding that metallothionein mRNA in the intestine

307 is most responsive to dietary cadmium in comparison with other organs extends, to the gene

308 expression level, observations that the intestine had the highest levels of the metallothionein

309 protein during dietary exposure of fish to cadmium (Berntssen et al., 2001a; Chowdhury et al.,

310 2005). Retention of dietary cadmium in rainbow trout is highest in the gut and lower in other

311 organs (Chowdhury et al., 2004b; Franklin et al., 2005; Ng et al., 2008), a pattern consistent with

312 our observations for metallothionein mRNA induction in Fundulus heteroclitus. The quantifiable

313 relationship between intestinal metallothionein expression and exposure to dietary cadmium in $F$.

314 heteroclitus may reflect a protective function for intestinal metallothionein. However, this

315 induction may not be without its own contribution to the toxicity of cadmium, since cadmium

316 transported out of the intestine as cadmium-metallothionein can be filtered and absorbed by the

317 kidney, a target of cadmium toxicity (Zalups et al., 2003).

319 While the mechanism for potentiation of cadmium-induced metallothionein expression by

320 benzo(a)pyrene is not known, our observations are consistent with an earlier report showing that

321 hepatic metallothionein induction in $F$. heteroclitus is enhanced after intraperitoneal injection of 
322 both cadmium and benzo(a)pyrene, in comparison with injection with cadmium alone (van den

323 Hurk et al., 2000). In addition, the levels of both hepatic cadmium and metallothionein are also

324 elevated in the Antarctic fish Trematomus bernacchii injected with a combination of 2,3,7,8-

325 tetrachlorodibenzo- $p$-dioxin (TCDD) and cadmium, when compared with induction by cadmium

326 alone (Regoli et al., 2005). Although the bioaccumulation pathway for benzo(a)pyrene and

327 cadmium in our study differed from that of these two studies, i.e., dietary to intestine versus

328 intraperitoneal injection to liver, the cellular mechanisms for regulating metallothionein gene

329 expression may be similar. It is interesting to note that, in higher animals, the signal transduction

330 pathways for benzo(a)pyrene and cadmium converge in the regulatory sequences in the

331 metallothionein gene. The upstream stimulatory factor one (USF1) is involved in regulation of

332 the metallothionein gene in response to cadmium (Andrews, 2000; Daniels et al., 2003; Datta et

333 al., 1997), and there is overlap of the sequence for the xenobiotic response element with that of

334 the USF1-binding site in the metallothionein I promoter (Takahashi et al., 1997). This suggests

335 that the potentiation by benzo(a)pyrene may lie in interactions at the level of transcriptional

336 regulation of the metallothionein gene.

338 At the broader level, our finding that benzo(a)pyrene potentiated intestinal metallothionein

339 induction by cadmium is of particular interest due to the fact that environments contaminated by

340 cadmium are often elevated in other substances such as polycyclic aromatic hydrocarbons. Based

341 on our findings, fish in such environments could display levels of metallothionein expression that

342 are higher than would be expected from cadmium exposure alone. However, the toxicological

343 significance of the increased induction is not clear-cut. For example, increased intestinal

344 metallothionein levels may further protect the intestine against cadmium toxicity and facilitate

345 retention of cadmium in the intestine. On the other hand, increased induction could also enhance 
346 metallothionein's role as the vehicle for the interorgan transport of cadmium from the intestine as

347 the cadmium-metallothionein complex. How potentiation of metallothionein expression by

348 polycyclic aromatic hydrocarbons such as benzo(a)pyrene affects the toxicodynamics and

349 toxicity of cadmium and, perhaps, other metals remains to be determined.

\section{Acknowledgements}

353 This study was supported in part by the Chesapeake Ecotox Research Project through an award 354 from Maryland Sea Grant to the University of Maryland Center for Environmental Science.

\section{References}

Andrews, G.K., 2000. Regulation of metallothionein gene expression by oxidative stress and metal ions. Biochem. Pharmacol. 59, 95-104.

ATSDR, 1999. Toxicological rofile for cadmium. Agency for Toxic Substances and Disease Registry, Atlanta, GA, U.S.A.

Baldisserotto, B., Chowdhury, M.J., Wood, C.A., 2005. Effects of dietary calcium and cadmium on cadmium accumulation, calcium and cadmium uptake from the water, and their interactions in juvenile rainbow trout. Aquatic Toxicology 72, 99-117.

Baldisserotto, B., Chowdhury, M.J., Wood, C.M., 2006. In vitro analysis of intestinal absorption of cadmium and calcium in rainbow trout fed with calcium- and cadmium-supplemented diets. Journal of Fish Biology 69, 658-667. 
368

Berntssen, M.H.G., Lundebye, A.K., Hamre, K., 2000. Tissue lipid peroxidative responses in Atlantic salmon (Salmo salar L.) parr fed high levels of dietary copper and cadmium. Fish Physiology and Biochemistry 23, 35-48.

Berntssen, M.H.G., Aspholm, O.O., Hylland, K., Bonga, S.E.W., Lundebye, A.K., 2001a. Tissue metallothionein, apoptosis and cell proliferation responses in Atlantic salmon (Salmo salar L.) parr fed elevated dietary cadmium. Comp. Biochem. Physiol. C-Toxicol. Pharmacol. 128, 299-310.

Berntssen, M.H.G., Lundebye, A.K., 2001b. Energetics in Atlantic salmon (Salmo salar L.) parr fed elevated dietary cadmium. Comp. Biochem. Physiol. C-Toxicol. Pharmacol. 128, 311-323.

Berntssen, M.H.G., Waagbo, R., Toften, H., Lundebye, A.K., 2003. Effects of dietary cadmium on calcium homeostasis, Ca mobilization and bone deformities in Atlantic salmon (Salmo salar L.) parr. Aquaculture Nutrition 9, 175-183.

Chowdhury, M.J., McDonald, D.G., Wood, C.M., 2004a. Gastrointestinal uptake and fate of cadmium in rainbow trout acclimated to sublethal dietary cadmium. Aquatic Toxicology $69,149-163$.

Chowdhury, M.J., Pane, E.F., Wood, C.M., 2004b. Physiological effects of dietary cadmium acclimation and waterborne cadmium challenge in rainbow trout: respiratory, ionoregulatory, and stress parameters. Comp. Biochem. Physiol. C-Toxicol. Pharmacol. 139, 163-173.

Chowdhury, M.J., Baldisserotto, B., Wood, C.M., 2005. Tissue-specific cadmium and metallothionein levels in rainbow trout chronically acclimated to waterborne or dietary cadmium. Arch. Environ. Contam. Toxicol. 48, 381-390. 
391

392

393

394

395

396

397

398

399

400

401

402

403

404

405

406

407

408

409

410

411

412

413

Dallinger, R., Prosi, F., Segner, H., Back, H., 1987. Contaminated food and intake of heavy metals by fish: a review and a proposal for further research. Oecologia 73, 91-98.

Daniels, P.J., Andrews, G.K., 2003. Dynamics of the metal-dependent transcription factor complex in vivo at the mouse metallothionein-I promoter. Nucleic Acids Research 31, 6710-6721.

Datta, P.K., Jacob, S.T., 1997. Activation of the metallothionein-I gene promoter in response to cadmium and USF in vitro. Biochem. Biophys. Res. Commun. 230, 159-163.

Elsenhans, B., Strugala, G.J., Schafer, S.G., 1997. Small-intestinal absorption of cadmium and the significance of mucosal metallothionein. Human \& Experimental Toxicology 16, 429-434.

Franklin, N.M., Glover, C.N., Nicol, J.A., Wood, C.M., 2005. Calcium/cadmium interactions at uptake surfaces in rainbow trout: Waterborne versus dietary routes of exposure. Environ. Toxicol. Chem. 24, 2954-2964.

Harrison, S.E., Klaverkamp, J.F., 1989. Uptake, elimination and tissue distribution ofdietary and aqueous cadmium by rainbow trout (Salmo gairdneri Richardson) and lake whitefish (Coregonus clupeaformis Mitchill). Environ. Toxicol. Chem. 8, 87-97.

Lehman, L.D., Klaassen, C.D., 1986. Dosage-dependent disposition of cadmium administered orally to rats. Toxicol. Appl. Pharmacol. 84, 159-167.

Livak, K.J., Schmittgen, T.D., 2001. Analysis of relative gene expression data using real-time quantitative PCR and the $2^{-\otimes \otimes \mathrm{Ct}}$ method. Methods 25, 402-408.

Lundebye, A.K., Berntssen, M.H.G., Bonga, S.E.W., Maage, A., 1999. Biochemical and physiological responses in Atlantic salmon (Salmo salar) following dietary exposure to copper and cadmium. Marine Pollution Bulletin 39, 137-144. 
414 Ng, T.Y.T., Wood, C.A., 2008. Trophic transfer and dietary toxicity of Cd from the oligochaete 415 to the rainbow trout. Aquatic Toxicology 87, 47-59.

416 Noga, E.J., 2000. Fish Disease-Diagnose and Treatment. Iowa State University Press, Ames, $417 \quad$ Iowa, USA, $367 \mathrm{pp}$.

418 Rana, S.V.S., 2006. Environmental Pollution: Health and Toxicology. Alpha Science 419 International, Ltd, Oxford, UK, $250 \mathrm{pp}$.

420 Regoli, F., Nigro, M., Benedetti, M., Gorbi, S., Pretti, C., Gervasi, P.G., Fattorini, D., 2005.

421 Interactions between metabolism of trace metals and xenobiotic agonists of the aryl

422 hydrocarbon receptor in the antarctic fish Trematomus bernacchii environmental 423 perspectives. Environ. Toxicol. Chem. 24, 1475-1482.

424 Szebedinszky, C., McGeer, J.C., McDonald, D.G., Wood, C.M., 2001. Effects of chronic Cd exposure via the diet or water on internal organ-specific distribution and subsequent gill

428 Takahashi, Y., Nakayama, K., Itoh, S., FujiiKuriyama, Y., Kamataki, T., 1997. Inhibition of the Cd uptake kinetics in juvenile rainbow trout (Oncorhynchus mykiss). Environ. Toxicol.

432 Thomann, R.V., Shkreli, F., Harrison, S., 1997. A pharmacokinetic model of cadmium in rainbow trout. Environ. Toxicol. Chem. 16, 2268-2274.

434 Van Cleef-Toedt, K.A., Kaplan, L.A.E., Crivello, J.F., 2001. Killifish metallothionein messenger 435 RNA expression following temperature perturbation and cadmium exposure. Cell Stress 436 \& Chaperones 6, 351-359. 
437 van den Hurk, P., Faisal, M., Roberts, M.H., 2000. Interactive effects of cadmium and

438 benzo[a]pyrene on metallothionein induction in mummichog (Fundulus heteroclitus).

439 Mar. Environ. Res. 50, 83-87.

440 Van Veld, P.A., Vogelbein, W.K., Cochran, M.K., Goksoyr, A., Stegeman, J.J., 1997. Route-

441 specific cellular expression of cytochrome P4501A (CYP1A) in fish (Fundulus

442 heteroclitus) following exposure to aqueous and dietary benzo[a]pyrene. Toxicol. Appl.

443 Pharmacol. 142, 348-359.

444 Vogelbein, W.K., Fournie, J.W., VanVeld, P.A., Huggett, R.J., 1990. Hepatic neoplasms in the 445 mummichog Fundulus heteroclitus from a creosote-contaminated site. Cancer Research $446 \quad 50,5978-5986$.

447 Wallace, W.G., Luoma, S.N., 2003. Subcellular compartmentalization of Cd and Zn in two 448 bivalves. II. Significance of trophically available metal (TAM). Marine Ecology-Progress $449 \quad$ Series $257,125-137$.

450 Zalups, R.K., Ahmad, S., 2003. Molecular handling of cadmium in transporting epithelia.

$451 \quad$ Toxicology and Applied Pharmacology 186, 163-188.

452

453 
454 List of Figures:

455

456 Figure 1. Representative real-time RT-PCR amplification profiles for intestinal, liver, and gill

457 metallothionein mRNAs in Fundulus heteroclitus exposed to dietary cadmium. The arrows point

458 to representative threshold cycles $\left(\mathrm{C}_{\mathrm{t}}\right.$ 's) of each tissue group on the $\mathrm{X}$-axis.

459

460 Figure 2. Dose-response relationship of ingested cadmium and levels of metallothionein mRNA

461 in Fundulus heteroclitus exposed to dietary cadmium. Levels of metallothionein mRNA were

462 determined by real-time qPCR and expressed as $2^{-\Delta \Delta C t}$ (Livak et al., 2001). $\mathrm{R}^{2}$ and significance of

463 regression coefficients: $\mathrm{R}^{2}=0.640, \mathrm{p}<0.006$ for intestine; $\mathrm{R}^{2}=0.001, \mathrm{p}<0.98$ for liver; and $\mathrm{R}^{2}=$ $4640.011, \mathrm{p}<0.79$ for gill. 
465 Table 1. Comparison of metallothionein mRNA levels in intestine, liver, and gill tissues in 466 control fish and fish exposed to dietary cadmium in the first experiment. Samples were analyzed by real-time PCR, and values are expressed as $2^{-\Delta \Delta \mathrm{ct}}$ (mean \pm 1 S.E., $\mathrm{n}=3$ for controls and $n=7$ or 8 for cadmium treated).

469

\begin{tabular}{lccc}
\hline & & \multicolumn{2}{c}{ Organ $^{*}$} \\
Treatment & \multicolumn{1}{c}{ Gill } & Liver & Intestine \\
\cline { 2 - 4 } & $0.108 \pm 0.051$ & $0.923 \pm 0.044$ & $0.611 \pm 0.243$ \\
Control & $0.176 \pm 0.055$ & $1.151 \pm 0.314$ & $6.510 \pm 1.000^{\star *}$ \\
Cadmium & 1.6 & 1.2 & 10.7 \\
Fold increase & & & \\
\hline
\end{tabular}

471 *Analysis of variance showed that differences due to the Treatment, Organ, and the

472 Organ $x$ Treatment interaction were significant $(p<0.002)$. The Tukey HSD test showed

473 that the Control treatment was significantly different from that of Cadmium. For the

474 effect of Organ, Intestine was significantly different from Liver and Gill, which were not

475 significantly different from each other $(p<0.05)$.

$476^{* *}$ The Tukey HSD test also showed that the Cadmium $\mathrm{x}$ Intestine interaction was

477 significantly different from all other combinations of Treatment $\times$ Organ, which were not

478 significantly different from each other. 
481 Table 2. Comparison of metallothionein mRNA levels in intestine, liver, and gill tissues

482 in control fish and fish exposed to dietary cadmium, benzo(a)pyrene, or a

483

484

485

486

\begin{tabular}{lccc}
\hline Treatment $^{*}$ & \multicolumn{3}{c}{ Organ $^{*}$} \\
\cline { 2 - 4 } & Gill & Liver & Intestine \\
\hline Control & $0.54 \pm 0.17$ & $0.81 \pm 0.25$ & $1.23 \pm 0.39$ \\
Cadmium & $1.24 \pm 0.39$ & $2.32 \pm 0.73$ & $24.52 \pm 7.75^{\star *}$ \\
Benzo(a)pyrene & $0.63 \pm 0.20$ & $1.27 \pm 0.40$ & $3.27 \pm 1.06$ \\
Combination & $1.92 \pm 0.60$ & $4.84 \pm 1.53$ & $42.70 \pm 12.80^{\star \star *}$
\end{tabular}
combination of cadmium and benzo(a)pyrene in the second experiment. Samples were analyzed by real-time PCR, and values are expressed as $2^{-\Delta \Delta C t}$ (mean \pm 1 S.E., $n=10)$

${ }^{*}$ Analysis of variance showed that differences due to the Treatment, Organ, and the 489 Organ $x$ Treatment interaction were significant $(p<0.001)$. The Tukey HSD test showed 490 that the Control treatment was significantly different from that of Cadmium and the 491 cadmium and benzo(a)pyrene Combination $(p<0.05)$. For the effect of Organ, Intestine 492 was significantly different from Liver and Gill, which were not significantly different from 493 each other $(p<0.05)$.

$494^{\star *, \star * *}$ The Tukey HSD test also showed that Cadmium x Intestine interaction was 495 significantly different from that of Combination $\mathrm{x}$ Intestine, and both of these 496 combinations were significantly different from all other combinations of Treatment $\mathrm{x}$ 497 Organ, which were not significantly different from each other. 
Fig. 1 Roesijadi et al.

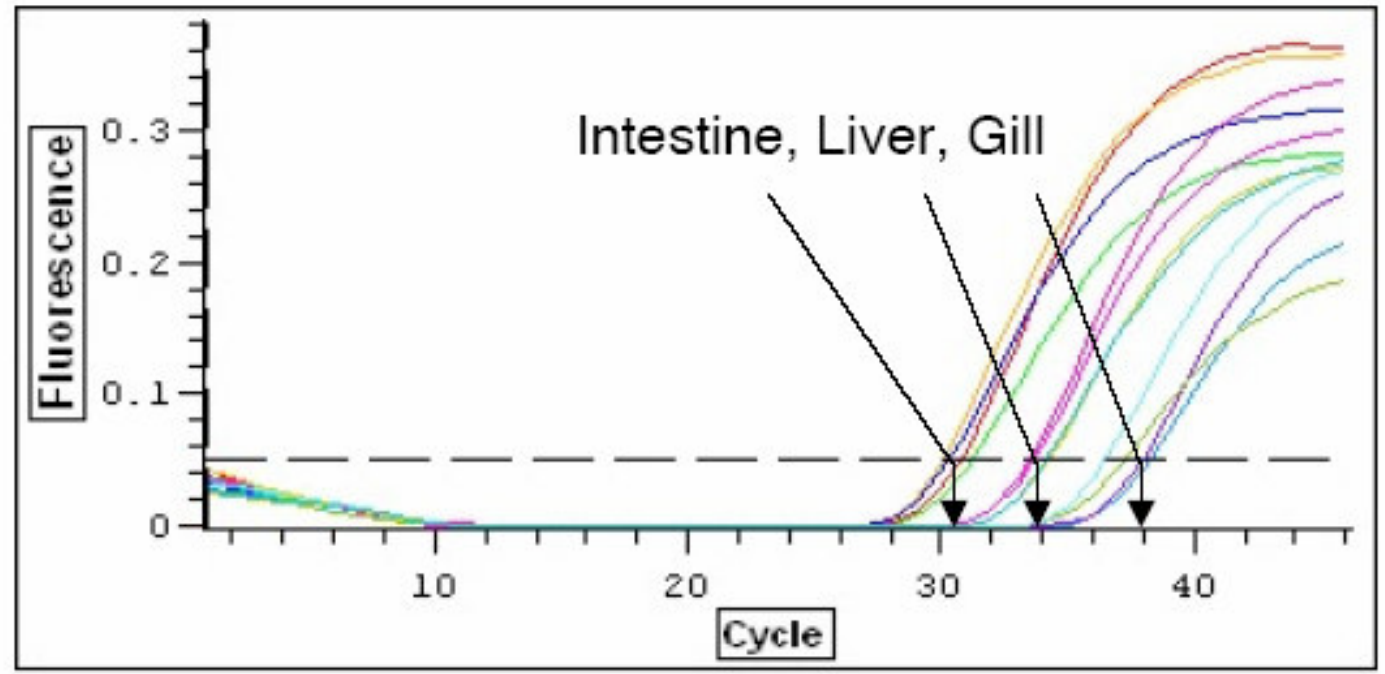

498 
Fig. 2 Roesijadi et al.

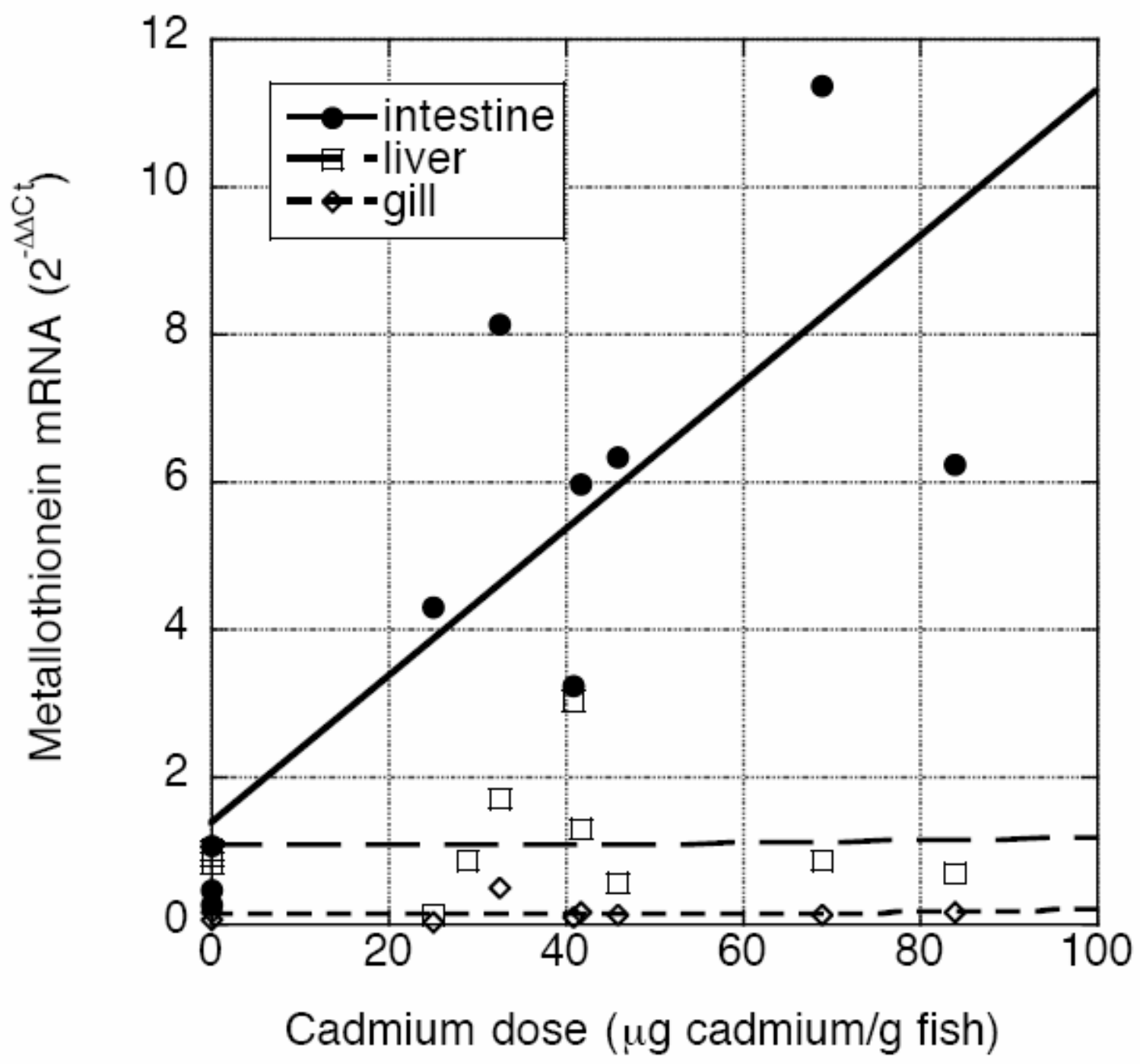

499

500 